\section{EL CONTROL DE LA VERDAD: LOS MURCIA DE LA LLANA, UNA FAMILIA DE CORRECTORES DE LIBROS}

\author{
Félix Díaz Moreno \\ Universidad Complutense de Madrid \\ Departamento de Historia del Arte II (Moderno) \\ fdiazmor@ghis.ucm.es
}

\section{THE CONTROL OF THE TRUTH: THE MURCIA DE LA LLANA, A FAMIL Y DEALING WITH BOOKS EDITING}

\begin{abstract}
The Murcia de la Llana family almost developed throughout a century one of the most significant tasks and as well more not knowing within the complicated process by which a manuscript had to pass until leaving the presss: the book correction. Through its hands they passed most of weitings of century XVII, many of which would later achieve a success without preceding case of the Quijote de Miguel de Cervantes. This study articulates on the basis of a series of the documentary news, many unpublished, that try to clarify the complex relation of kinships, as well as interesting data on the office of general book corrector.
\end{abstract}

KEY WORDS: Murcia de la Llana; book corrector; fe de erratas; Cervantes; printign; 17th century.

Si nos acercamos a alguno de los libros de nuestro Siglo de Oro comprobaremos cómo los apellidos Murcia de la Llana se perpetúan en los pliegos de preliminares de manera palmaria. Su oficio de correctores generales de libros les ofreció la oportunidad de aparecer, aunque modestamente, junto a los nombres de literatos de la talla de Cervantes, Lope, Quevedo o Calderón, entre muchos otros; así como de una pléyade de escritores de las más variadas temática y condición.

A pesar de la importancia otorgada a la corrección de libros dentro del proceso editorial durante los sucesivos reinados de los Austrias', no disponemos de textos específicos en donde se contengan el método, funciones y caracteristicas propias del oficio. El desarrollo de sus actuaciones se basaría en preceptos consuetudinarios que con el paso del tiempo se convirtieron en normas precisas, aunque por razones que desconocemos, éstas no se convirtieron en textos legales codificados.
RESUMEN: La familia Murcia de la Llana desarrolló a lo largo de casi un siglo una de las tareas más significativas y a su vez más desconocidas dentro del complicado proceso por el que un manuscrito debía transcurrir hasta abandonar la imprenta: la corrección de libros. Por sus manos pasaron la mayor parte de los escritos del siglo XVII, muchos de los cuales alcanzarian posteriormente un éxito sin precedentes, caso del Quijote de Miguel de Cervantes. Este estudio se articula en base a una serie de noticias documentales, muchas inéditas, que intentan esclarecer la compleja relación de parentescos, así como interesantes datos sobre el oficio de corrector general de libros.

PALABRAS CLAVE: Murcia de la Llana; corrector de libros; fe de erratas; Cervantes; imprenta; siglo XVII.

La principal función del corrector, en origen parece simple: cotejar el texto manuscrito con el ejemplar impreso para verificar que su traslado ha sido exacto. Pero este elemental planteamiento se encontrará plagado de problemas tanto a nivel profesional como corporativo por parte de los libreros-impresores.

Para llegar a entender el complejo proceso por el que atravesaba el libro desde que se encontraba manuscrito, hasta llegar a su venta en las librerías, así como los planteamientos legislativos sobre los que se fundaban estas actuaciones hasta desembocar en el siglo XVII, bueno será esbozar el contexto del mismo².

Tras el inicial apoyo y protección que los Reyes Católicos otorgaron a la incipiente imprenta, así como a los primeros ejemplares que surgieron de ella, ya fueran nacionales o foráneos; se reconsideró la importancia de la misma y sus efectos en base a nuevos planteamientos más proclives 
a un mayor control editorial. Con este referente, el 8 de julio de 1502 se establece un primer ordenamiento en el que quedan definidos alguno de los procedimientos para poder pedir las autorizaciones pertinentes anteriores a la publicación de un libro3.

Uno de los de mayor alcance consistía en la petición de licencia de impresión, para lo cual era condición ineludible contar con la aprobación del arzobispo de Toledo, Sevilla, Granada, Burgos o Salamanca; o en su defecto con la del presidente de la Audiencia de Valladolid ${ }^{4}$. En 1554 se reestructura este formalismo pasando de ser los prelados los que otorguen su autorización, al presidente del Consejo Real con lo que se centralizaba este requisito; sólo cuatro años más tarde y debido al nerviosismo originado por la aparición de focos luteranos en el reino, se decidió que las hojas de los manuscritos originales deberian ir firmadas por uno de los escribanos de Cámara. Una vez en el Consejo de la Cámara además de la verificación expresada sería escrupulosamente tamizado por un censor, para cuyo menester se acudia a personas doctas en la materia evaluada, si bien los religiosos coparon buena parte de esta actividad; tras el examen se emitía un dictamen positivo o contrario al requerimiento.

También en el Consejo, aunque "firmado" por el rey se realizaba el Ilamado Privilegio, actuación por la cual el autor podía imprimir su obra de forma exclusiva durante un número determinado de años, normalmente diez. Otro de los condicionantes, era la licencia eclesiástica rubricada por el Vicario General del Obispado, aunque ésta en muchos casos se obvió.

Si los Reyes Católicos y su nieto el Emperador estuvieron atentos a la creciente e influyente importancia de la imprenta, no les fue a la zaga Felipe II quien aplicó estrictas normativas de control y censura, que abarcaron un amplio espectro del mundo editorial y que posteriormente se trasladaron a las recopilaciones legislativas sucesivas convirtiéndose en ejemplos a seguir. Una de las de más amplio calado fue la Pragmática-sanción datada en Valladolid el 7 de septiembre de 1558 firmada por la princesa doña Juana, en nombre del monarca 5 .

De las diferentes disposiciones que engloba esta norma, cabría destacar según aludíamos anteriormente la obligación de presentar el original de la obra al Consejo Real para ser aprobada por la persona o personas nombradas por el mismo y así recibir la licencia; si no se obraba de esta forma las penas eran la muerte para el infractor así como la pérdida de todos sus bienes y la quema de los ejemplares. También para evitar fraudes en obras con licencia aprobada, el ejemplar manuscrito entregado al Consejo debía ir firmado por un escribano de Cámara haciendo constar el número de "cada plana y oja"; así mismo debían aparecer las enmiendas, cuando fueren pertinentes, realizadas a la obra. Una vez cubiertos todos estos prolegómenos, el original era impreso en una primera "muestra" y tras la oportuna revisión llevado nuevamente al Consejo donde se certificaria la exactitud, licencias y demás condicionantes para poder salir de los tórculos.

Tras franquear estas y otras cláusulas, el manuscrito junto con las pruebas de imprenta, volvía nuevamente a uno de estos establecimientos para su tirada definitiva y posterior comercialización, pero antes de llegar a este extremo, el original había salvado tanto las correspondientes disposiciones reglamentarias, como dos filtros en cuanto a la rectificación cambio y enmienda de las oportunas erratas convenientemente señaladas.

\section{Del Ars Impressoria al Ars Corrigenda}

Las primeras noticias que disponemos acerca de la profesión de corrector de libros nos la brinda un documento de 1565 en el cual se hace referencia expresa a los derechos establecidos sobre el cobro de emolumentos:

"En Madrid a nueue dias del mes de Noviembre de mil y quinientos y sesenta y cinco años, en la consulta que tuuo con su Majestad el señor Licenciado Morillas: Lo de los derechos que han de lleuar el Corrector de los libros, que sea a respeto de lo impresso, y no del original"6.

Otro importante testimonio nos lo ofrece el que fue durante muchos años corrector general: el doctor Juan Vázquez del Mármol. Su monopolio fue continuamente contestado por los libreros-impresores, quienes al final, como posteriormente comprobaremos lograron sacar adelante sus reclamaciones. Se conserva un manuscrito en la Biblioteca Nacional de Madrid en donde Vázquez del Mármol, entre muchas otras anotaciones, hace referencia a las "Con- 
diciones que se pueden poner cuando se da a imprimir un libro"; entresacamos ahora aquellas que se ajustan a nuestro propósito:

"6. Que ha de tener [el impresor] buen Corretor, que corrija las probas a gusto del autor.

7. Que ha de sacar dos o tres probas, las que se concertaren, si el autor quisiera corregirlas.

8. Que en este caso envie las probas al autor a tiempos acomodados que tenga lugar de corregirlas.

9. Que las ha de enmendar a la letra, como se las enmendare, sin dejar errata ninguna, aunque para esto sea menester adelantar un día o jornada"7.

La existencia de un corrector general de imprentas nombrado por el Rey, había quedado establecido tras la mencionada legislación que centralizaba esta tarea en una sola persona. Tenemos alguna referencia indirecta de su creación por una carta y memorial que Pedro López de Montoya dirigió el 19 de julio de 1588 a Mateo Vázquez de Lecca, pidiendo la creación de una plaza de "Censor General" al igual que ya existía la de "Corrector General".

Para saber cuáles eran las funciones de los correctores, además de lo ya indicado, podemos seguir la narración que a principios del siglo XVII realizó Cristóbal Suárez de Figueroa ${ }^{9}$ en la cual quedan marcadas las diferentes fases por las que transitaba el manuscrito hasta convertirse en impreso; asi tras haber combinado el "componedor" o "cajista" la estructura escrita de cada plancha con sus correspondientes espacios:

"Llevase tras esto a la prensa, donde se saca una muestra que llaman prueba, dándose al Corrector para que corrija las mentiras, y las enmiende el componedor. Estampase al fin en la prensa, llamando tirar a semejante operación... Toca al Corrector corregir las mentiras, señalándolas; comprobar para ver si están correctas, mirar las concordancias, folios y signaturas, con otras cosas advertidas ya en el discurso de los Correctores"10.

También nos indica algunos de los instrumentos que usaban los correctores para desarrollar sus funciones:

"Para la facultad de Correctores servirá por estremo toda la suma que precede al Diccionario de Fray luan de Genova: sin la regla del Prisciano en Latin. Quanto a la Ortografía
Castellana, se hallan diferentes opiniones, particularmente sobre las letras vocales y consonates: mas comúnmente se sigue la de las Imprentas de Madrid, como entre otras la de Luis Sánchez, donde asiste por corrector Gonzalo de Ayala, sujeto no menos culto que ingenioso"11.

Una vez establecidas algunas de las pautas sobre las que se guiaban los profesionales de este oficio, volveremos a retomar la polémica surgida en el siglo XVI con respecto al corrector general, ya que de ella surgirá una diversificación en estos menesteres.

Tras ocupar el cargo Herrera Maldonado ${ }^{12}$, le sustituyó desde los años setenta Juan Vázquez del Mármol, quien acaparó y luchó de manera denodada por mantener el privilegio que le había sido concedido. Tras las leyes implantadas por Felipe II, el malestar de los libreros-impresores se fue acrecentando, entre otras cuestiones por el requisito sobre la corrección del texto por parte del corrector general, cuyo trabajo se dilataba sobremanera en el tiempo al tener que pasar por las manos de una sola persona una gran parte de los manuscritos de la Corona.

El retraso que se producía debido a la lentitud del proceso, ocasionaba fuertes pérdidas al gremio de los impresores, ante lo cual decidieron proponer nuevas fórmulas para la mejora del proceso.

Para ello se unieron los libreros sevillanos, salmantinos y madrileños ${ }^{13}$, quienes expusieron al Rey y al Consejo Real sus quejas, así como sus posibles soluciones. Éstas pasaban, o bien, por la autorización de que cada ciudad nombrara su propio corrector, dependiente a la postre del Consejo Real, 0 bien, que se encargase a las universidades esta función.

Los primeros en solventar sus problemas fueron los salmantinos, obteniendo por la provisión real de 23 de diciembre de 1580, la autorización expresa de que la Universidad de Salamanca nombraría un corrector para juzgar aquellas obras editadas por autores e impresores dependientes de la aludida institución. Por su parte los libreros madrileños consiguieron la misma merced para la Universidad de Alcalá de Henares por provisión real de 6 de junio de 1582. Progresivamente también se concedió a las universidades de Valladolid, Toledo, Granada y Burgos. Sin embargo, muchos más problemas de los esperados tuvieron los libreros-impresores sevillanos, ya que cometieron 
la imprudencia de poner nombre propio a sus problemas que no era otro que Vázquez del Mármol, quien ante la posibilidad de perder otra buena parte de su exclusividad se opuso de manera tajante ${ }^{14}$.

Así pues, a finales del siglo XVI el panorama que se nos presenta respecto a la corrección de libros había variado de forma palpable. A pesar de las mejoras en el sistema, los problemas continuarán, sobre todos los derivados de la intromisión de funciones entre los correctores de las ciudades universitarias y el corrector general del Consejo Real. Esta misma controversia se arrastrará en la siguiente centuria, donde veremos aparecer a un clan familiar que a lo largo de los años desarrollará de manera ininterrumpida el ejercicio de su actividad con resultado dispar.

\section{ESTE LIBRO CONCUERDA CON SU ORIGINAL...}

Ésta es la consabida frase con la que el corrector general da el visto bueno a una obra. Fórmula que fue utilizada por toda una estirpe que, a lo largo del siglo XVII y parte del XVIII, desempeñarán la consabida profesión.

Si bien conocemos abundantes datos biográficos del fundador de la dinastía, no así de su parentela, en cuyo estudio se ha instalado una cierta confusión debido tanto a la falta de noticias como a la dificultad añadida de encontrar cuatro homónimos entre su descendencia actuando con idéntica actividad. Intentaremos pues desentrañar y ofrecer luz sobre esta dinastía tan ligada al mundo del libro en nuestro Siglo de Oro, bajo cuya atenta mirada, no siempre minuciosa, pasaron las letras originales de literatos, arquitectos, filósofos, cronistas, militares, religiosos, geógrafos, pintores... y un largo etcétera.

El iniciador de esta profesión en la familia fue Francisco Murcia de la Llana, cuyo campo de acción no se limitó a la corrección sino que ejecutó otras actividades literarias más profundas como fueron las de traducir varias obras de Aristóteles o las Súmulas de Villalpando.

Sobre su biografía existen variadas e interesantes referencias, siendo algunas casi coetáneas, así por ejemplo Nicolás Antonio nos ofrece una primera aproximación: "Professor Complutensis philosophiae, atque in Collegio Theologorum sodalis, edidit, partim vernacule partim Latine, Cursum ut vocant Artium integrum, scilicet"15. Aunque la mayor parte de los datos que tenemos hoy en día pertenecen a las investigaciones que sobre él introdujo Pérez Pastor.

Francisco Murcia de la Llana era natural de la localidad conquense de Priego, hijo de Martín de Murcia a su vez nacido en la villa del Campo y de Maria Duro de la Llana natural también de Priego; otros hijos del matrimonio fueron Diego, Juan y Juana ${ }^{16}$, del primero conocemos que residió en Ciudad de México hasta su muerte, sin embargo de los otros nada sabemos. A raíz de su traslado a Madrid menudearán las noticias sobre las actividades de Francisco, primero en Alcalá de Henares y posteriormente en la corte ${ }^{17}$.

En la ciudad complutense aparece como licenciado y colegial en el Colegio de la Madre de Dios de los Teólogos, lugar éste en el que se unirán las luces y las sombras de sus actividades correctoras. Desde el año 1601 actuaba como corrector ordinario de la universidad, conjuntamente con los licenciados Vicuña, Cristóbal de Orduña, el doctor Alonso Vaca de Santiago y otros.

En 1604 se le presentó un manuscrito de una novela que si bien podía haber sido uno de sus logros, con el paso del tiempo y el detenido estudio se ha convertido en su cruz. Nos referimos al Quijote, obra capital sobre la que Francisco Murcia rubricó el célebre "Este libro no tiene cosa digna [de notar] que no corresponda a su original", cuando la realidad demuestra que las erratas campean por el texto de manera más que clara y las omisiones desvirtúan partes del mismo, apareciendo ya en el propio título y en capitulos interiores $^{18}$.

A partir de 1607 aparece en Madrid; en los documentos referidos actúa a veces como pagador (censos, compras de papel, casas, etc.), y otras como receptor (alquileres, censos, etc.). Por ellos hemos podido hacer un seguimiento de sus diversos asentamientos en el centro de la villa. Así en el año arriba mencionado habitaba en la calle Mayor en casas de Carlos Musitelli; un año después compró unas casas junto a la Puerta del Sol. En 1610 tiene otra en la esquina con la calle de San Jacinto adonde se traslada en 1611, quedando la de la Puerta del Sol primero en alquiler y posteriormente ocupada por Martín Murcia en 1615. Sabemos también que ya en 1622 vive en la Plaza Mayor 
junto a la escalera que baja a la cava de San Miguel y que en 1623 alquilaba la casa de la calle de San Jacinto.

Probablemente ya en Madrid, se casó con doña Clara de Ribas, natural de la corte e hija de Carlos Pablo de Ribas y María Ortega. Al contraer matrimonio también adquirió la obligación de ejercer la curaduría del licenciado Francisco de Ortega y de los hermanos de su mujer: Carlos Pablo (escribano real), Ignacio (contador), Gabriel (profeso en San Francisco), Juan, Miguel († 1608) y Francisca ${ }^{19}$.

Debido al prestigio personal derivado de sus actividades como traductor y compilador de famosas obras trasladadas al latín o al castellano, así como su experiencia en el mundo de la corrección de libros, hicieron que tras el cese en la actividad de Vázquez del Mármol, el rey nombrara a Francisco Murcia de la Llana como nuevo corrector general de libros. Así por cédula real, otorgada el 9 de abril de 1609 se dispensa la mencionada merced con un sueldo de 40.000 maravedís anuales librados en penas de Cámara, los cuales se beneficiaron de un aumento de 10.000 maravedis en $1612^{20}$; además de ello cobraría como emolumentos ocho maravedís del derecho de corrección de cada pliego con su original, tasa ésta que se vería incrementa en 1618 a 17 maravedís. Dos años más tarde, concretamente el 24 de abril, Francisco Murcia eleva una petición para aumentar sus honorarios ${ }^{21}$.

Su solicitud se fundamentaba en el perjuicio sufrido por la falta de mercedes otorgadas. Por ejemplo, la casa de aposento que habian disfrutado sus antecesores, nunca le fue concedida; tampoco mercedes pecuniarias a modo de pensión, o alguna capellanía ${ }^{22}$. Asimismo manifiesta, que gran parte de lo que cobra lo destina a sufragar el sueldo de un oficial que actuaba de apoyo en dicha labor. A todo ello habría que sumar la realidad cotidiana por la cual ante el precio, estimado generalmente como alto, de los pliegos corregidos, existió una marcada tendencia a llevar los originales a otras ciudades (Alcalá, Valladolid y Salamanca) donde el importe por la misma actividad fluctuaba entre los 10 y 12 maravedís. Ante todo ello Francisco Murcia pide un acrecentamiento de salario hasta los 600 ducados anuales. La petición fue estudiada por la Cámara quien accedió satisfactoriamente a sus demandas elevando el salario de los 50.000 a los 100.000 maravedís anuales, como contraprestación bajaba los derechos de corrección de 17 a 10 maravedis para hacer más competitiva la men- cionada corrección ${ }^{23}$. Pero la resolución favorable no se hizo efectiva, como posteriormente comprobaremos por otras peticiones.

En diciembre de 1635, Francisco Murcia, obtiene sin embargo del rey una merced cuyas consecuencias se perpetuará en el tiempo ${ }^{24}$. Ésta no era otra que la obtención de licencia y facultad para poder otorgar, bien en vida o tras su fallecimiento, el título de corrector a uno de sus hijos. La decisión contaba con el visto bueno real y de la Cámara que ya en noviembre había estudiado una consulta previa para la habilitación de esta merced ${ }^{25}$.

Este dato sobre la concesión del título de corrector general en uno de sus hijos, tradicionalmente ha sido interpretada por todos los autores, como la cesión del mismo a su hijo mayor, pero la localización y lectura de nuevos documentos nos han llevado a plantearnos esta aseveración con marcados matices.

Efectivamente, en diciembre de 1635 Francisco Murcia obtiene la merced aludida, pero al contrario de lo que podría parecer en un primer momento la propiedad del cargo no recae en su hijo homónimo, sino en su hija María Murcia de la Llana ${ }^{26}$. Las cláusulas del nombramiento establecian que el cargo sería para doña María hasta que "tomase estado" pasando en ese momento a su consorte; mientras que ello se producía el oficio sería desarrollado por su hermano Francisco Murcia ${ }^{27}$. Otra de las condiciones era reservar de los gajes obtenidos un total de 60 ducados anuales para las otras tres hermanas: Josefa, Catalina y Antonia ${ }^{28}$. Creemos que el motivo de esta decisión sería solventar un impedimento añadido ya que Francisco Murcia pertenecía al estado religioso y sus obligaciones no le permitirian desarrollar el cargo en toda su extensión, aunque finalmente tendría que claudicar debido a las circunstancias desfavorables. Otra de las disposiciones establecía claramente que en caso de rechazar este oficio doña Maria, el cargo de corrector pasaría a su hermano Francisco.

Para añadir más confusión al asunto y ante la situación creada, -en la cual doña María poco o nada sabía del oficio y su hermano Francisco se veía imposibilitado para cumplir los cometidos otorgados debido al desempeño de sus funciones dentro de la Compañía de Jesús-, Francisco Murcia padre, optará de manera provisional por nombrar como corrector general de libros, en tanto que la situación 
se solventara, a otro de sus hijos, en este caso a Carlos Murcia de la Llana, quien a lo largo del siglo lo ocupó de manera discontinua; el nombramiento se efectuó el 23 de julio de $1636^{29}$.

Cuando el asunto parecia estar zanjado nuevas circunstancias obligaron a trastocar los planes marcados. Al dictar sus últimas voluntades, Francisco Murcia hace mención expresa al permiso especial que recibió su hijo Francisco para abandonar la Compañía; con ello se pretendía que el mencionado pudiera hacerse cargo de la subsistencia de sus padres y hermanas menores ${ }^{30}$. También entre sus últimas voluntades suplica al rey que le otorgue una merced en cuanto a una ocupación correspondiente a su "persona y letras"; así mismo el testador se ratifica en el nombramiento que hizo de corrector de libros en su hijo Carlos. El problema vuelve a surgir cuando doña María decidió no casarse y profesar en un convento; este hecho, a su vez, iniciaba un nuevo cambio en la corrección de libros, puesto que según se desprendía de una de las cláusulas anteriormente citadas, ante la renuncia del derecho de doña María el título pasaba directamente a su hermano Francisco. El cese del derecho se produjo el 10 de diciembre de 1639 ante el ya consabido escribano de su majestad Carlos Pablo, como contrapartida se remuneraba a doña María con 30 ducados anuales, establecidos además de los 60 para las hermanas ${ }^{31}$. El título del oficio se concedió rápidamente a Francisco, ya libre de otras ataduras, el 17 de enero de 1640 por cédula real, con las mismas calidades, salarios y preeminencias de las que había gozado su padre ${ }^{32}$.

Una vez realizado el nombramiento desarrolló personalmente la actividad entre 1640 y 1651. En este último año, una nueva empresa vendría a paralizar transitoriamente su gestión al frente de la corrección de libros; en su calidad de presbitero y doctor, se le requirió para embarcar hacia las Indias en la "... armada de las galeras de España en servicio del señor duque de Alburquerque general de ellas y por Vicario general de lo eclesiástico de las dichas galeras..." ${ }^{\prime 3}$. En el ínterin de este viaje sin retorno, delegará sus funciones como corrector nuevamente en su hermano Carlos (17 de abril de 1651); esta eventualidad se mantendrá hasta su muerte en tierras americanas acaecida en 1665. Y si de óbitos hablamos cabe destacar aquí otras de las facetas de Francisco, en este caso como poeta, quien ante la prematura muerte de don Cristóbal de Oñate hizo compilar ${ }^{34}$ y escribir diversas glosas laudatorias provenientes de heterogéneas personalidades, lo que le valió incluso el reconocimiento de Lope de Vega:
Si de Francisco Murcia de la Llana,
Hijo de aquel Varón tan eminente,
Que duplicó laureles en su frente,
En la lengua latina y Castellana,
Divina quieres ver la Lyra humana
Sus fúnebres canciones oye atento,
Verás que la dulçura de su acento
Templó en el Polo Antártico la muerte
Del joven de Cantabria heróico y fuerte,
Que de veinte y dos años (cosa estraña!)
Murió desando un nuevo Reyno a España"35.

Tras la muerte de Francisco, el rey nuevamente despachará una cédula reconociendo la labor desarrollada por la familia Murcia de la Llana y a su vez depositando la confianza en el nuevo corrector general de libros en la persona de Carlos, lo que acontece en febrero de $1665^{36}$.

Carlos Murcia de la Llana, además del título aludido fue abogado de los Consejos desde su examen el 14 de marzo, asesor de las Guardas españolas desde 9 de noviembre de 1655 nombrado por don Luis Ponce de León y ratificado en 1662 por el marqués de Salinas; también ejerció la jurisdicción civil y criminal de los soldados de las guardias en la campaña de Francia de 1660 ante la ausencia de don Cristóbal Gaviria.

Pero el nombramiento y cargo oficial poco le duraron a don Carlos, puesto que fallecía el 3 de mayo de 1668 dejando nuevamente vacante la plaza. Ante esta situación su viuda doña Josefa de Montaña se dirigió a la Cámara de Castilla con un memorial en el que solicitaba una gracia especial ${ }^{37}$. Al morir Carlos había dejado un huérfano de ocho años que siguiendo la tradición familiar también se llamaba Francisco Murcia de la Llana, para el cual solicitaba su madre el titulo de corrector, aduciendo los méritos tanto de su marido como de los anteriores familiares en el cargo; manifestaba también la falta de medios ante los gastos surgidos por la larga enfermedad de su cónyuge, y el desvalimiento en el que se quedaban las tres hermanas del finado. Ante tal cúmulo de razones, nuevamente el rey otorgó su aquiescencia; con celeridad, su madre actuando como tutora comenzó a buscar un corrector de confian- 
za que detentara el oficio hasta la mayoría de edad de Francisco.

La decisión por parte de doña Josefa no se hizo esperar debido a que la persona elegida venía desarrollado el mismo trabajo junto a su marido, por lo que conocía suficientemente el oficio; el nombramiento recayó en don Juan de Ayala Manrique ${ }^{38}$. El asunto se complicó a los pocos meses debido a la repentina muerte de don Juan; por certificación de don Sebastián de Fozo, teniente de cura de la parroquial de San Sebastián, se hacia constar el fallecimiento el 30 de diciembre de 1668 y su entierro en el convento de la Victoria $^{39}$. De nuevo comenzaron los trámites y el 5 de enero de 1669 ya se tenía un nuevo candidato, en esta ocasión don Francisco Forrero de Torres, abogado de los reales Consejos, quien parece ser que no tuvo mayores problemas para ejercer el cargo hasta su relevo por Francisco.

A este último le encontramos en 1680 entablando un pleito por competencias con el corrector de la universidad alcalaína ${ }^{40}$. El litigio se planteó cuando el corrector nombrado por la Universidad de Alcalá, Diego de Bárcena ${ }^{41}$, mandó al Consejo las correcciones realizadas a un libro escrito por el padre fray Carlos Chavarría de la Compañía de Jesús; al llegar a Madrid fue nuevamente anotado por Francisco Murcia quitando las correcciones anteriores. A finales de septiembre el pleito continuaba. El 26 de enero de 1682 se paraliza momentáneamente ante la muerte de Bárcena y posterior sustitución por el licenciado Pedro de Contreras. El 2 de marzo del mismo año, y ante la reunión celebrada en la Cámara rectoral del Colegio Mayor de San Ildefonso, se decide mandar al nuevo corrector a Madrid para defender los intereses de la Universidad ${ }^{42}$, en un intento más por perpetuar sus prerrogativas aprobadas como ya veíamos en 1582.

Al morir el hijo de Carlos Murcia y doña Josefa Montaña, y ante la vacante del título, será otro componente de esta familia quien intente acceder al puesto; esta información la hemos obtenido gracias al borrador de una carta ${ }^{43}$, donde se expresa la anhelada demanda. En ella Francisco Murcia (y van cuatro), hijo de Martín Murcia ante la muerte de su primo hermano al que nombra como presbitero, plantea la posibilidad de recibir la merced aportando en su argumentación el currículo profesional de toda la familia, en cuanto a la fecha apunta: "... y respecto de que de cient años a esta parte a estado [el oficio de corrector] en esta familia..."; estaríamos por tanto alrededor de 1709.
Si bien de él no hemos obtenido mayor información, sí que disponemos de algunas referencia acerca de su padre, gracias a la documentación generada al recibir la merced de un hábito de Santiago ${ }^{44}$. De él se desprende que Martín Javier Murcia de la Llana, hijo de Francisco Murcia y doña Clara de Ribas, era natural de Madrid y fue bautizado en la parroquial de San Miguel el mes de septiembre de 1628 y aunque los trámites para el hábito comenzaron en 1670 no se despachó el título de caballero de la orden de Santiago hasta el 26 de enero de 1671. Que nosotros conozcamos, no ejerció en ningún momento el cargo de corrector de libros, sin embargo si ocupó diferentes cometidos como fue el de Comisario del Santo Oficio y el 5 de mayo de 1684 entró como congregante en la venerable del apóstol San Pedro de sacerdotes naturales de Madrid; falleció este mismo año y fue enterrado el primero de noviembre en el monasterio de religiosas jerónimas del Corpus Christi ${ }^{45}$.

El último capítulo de esta dinastía de correctores se escribirá durante los años veintes del siglo XVIII. De nuevo tenemos a un Murcia de la Llana ejerciendo el oficio; en esta ocasión no sabemos con seguridad la línea de parentesco, aunque nos decantamos porque fuera otro de los hijos de Martín Javier o de su primogénito Francisco. Su nombre Carlos Murcia de la Llana, corrector que ha pasado inadvertido durante muchos años; la verificación de su existencia nos ha llegado al encontrar una carta donde aparece como tal enmendando la plana al autor de un libro ${ }^{46}$, que acababa de ser impreso en 1726; éste era una cartilla donde se exponían técnicas para torear a caballo redactado por Nicolás Rodrigo Noveli.

El libro apareció con las pertinentes licencias y aprobaciones, pero sin embargo no se encuentra impresa la fe de erratas; este último punto unido a algún otro condicionante personal, que desconocemos, hizo que Carlos Murcia de la Llana, corrector por su Majestad criticara abiertamente la edición con duras palabras que iban desde la demostración general del libro hasta la corrección de cada uno de los capítulos del mismo ${ }^{47}$.

Entre los zaherimientos que lanza al autor destacan: "Primeramente, la Dedicatoria [al duque del Arco], esa, se borre, que cosa para niños de la escuela, no es digna de ofrecerse a un hombre grande..." "En la tassa de cada pliego, diga, no vale nada, quedando satisfecho el Escriptor con estar tan pagado de si mismo..." "En lugar de adver- 
tencias hechas al lector, se le deben hazer al Autor...". Pero para rematar la faena, apropiándonos del símil taurino, Carlos Murcia dedicó unas hirientes coplillas ${ }^{48}$ que firmó en el Buen Retiro el 25 de julio de 1726:
Remito esa Fee de Erratas, que asi intitulo á las notas que en la tuya me denotas; y si el tiempo me dilatas, y de darme treguas tratas, protexto con fee sencilla, por ver si el autor humilla, su Cartilla á esta mi fee, sin salir del A. B. C. leerle mas bien la Cartilla.

Con él, damos por finalizado este breve acercamiento a una familia cuya influencia se dejó sentir en el mundo librario de la corona y cuya perpetuación supuso un verdadero monopolio en el control por la verdad, no tanto como un elemento de configuración y conformación de textos, sino como un instrumento legislativo tendente a evitar falsas ediciones perniciosas al reino y a sus gobernantes. Entre la ingente nómina de autores que pasaron por sus manos, encontramos tanto los libros de figuras consagradas, como de aquéllas, que por mudanza de la fortuna nunca traspasaron el umbral del Parnaso; al igual que el caprichoso destino de los textos, de sus autores y de sus correctores y parafraseando al poeta y gramático Terencio Mauro cuando sentenciaba que los libros tenían su propio hado, concluimos, sea pues: Habent sua libelli. VALE.

\section{NOTAS}

1 Sobre el libro antiguo en nuestro pais, existe una rica bibliografía que se acrecienta día a día; sólo a modo de referencia, centrándonos en los contenidos referidos: González de Amezúa y Mayo, Agustín: "Cómo se hacía un libro en nuestro Siglo de Oro", en Opúsculos Histórico-Literarios, CSIC, tomo I, Madrid, 1951, pp. 331-373. Centrado en la Corona de Aragón: Madurell Marimón, J. M.a: "Licencias reales para la impresión y venta de libros (1519-1705)", en Revista de Archivos, Bibliotecas y $\mathrm{Mu}-$ seos, LXXII, 1-2 (1964-1965) pp. 111248. Mateu y Llopis, F.: "Licencia, tasa y privilegio de impresión en la España de los siglos XVI y XVII", en Guttenberg-Jahrbuch, 1965, pp. 197-200. Moll, Jaime: "El libro en el Siglo de Oro", en Edad de Oro, Universidad Autónoma de Madrid, I, 1982, pp. 4354. Simón Díaz, J.: El libro español antiguo. Análisis de su estructura, Edition Reichenberger, Kassel, 1983, Idem: "Algo más acerca de la estructura del libro antiguo español", en
Varia Hispánica: Estudios en los Siglos de Oro y Literatura Moderna: Homenaje a Alberto Porqueras Mayo, Ed. Reichenberger, Kassel, 1989, pp. 429442. W. AA.: El libro antiguo español, Actas de los coloquios internacionales, Salamanca, 1988 (I), 1992 (II), 1996 (III) y 1998 (IV y V). García Oro, J.: Los reyes y los libros. La política libraria de la Corona en el Siglo de Oro (1475-1598), Ed. Cisneros, Madrid, 1995. W. AA.: Mundo del libro antiguo, dirigido por Francisco Asin, Ed. Complutense, Madrid, 1996. Moreno Gallego, Valentín: "Nescit vox missa reverti: cuatro palabras sobre el control de la escritura en la modernidad española", en La investigación y las fuentes documentales de los archivos, ANABAD, Guadalajara, 1996, pp. 1155-1174. Bouza Álvarez, Fernando: "Para qué imprimir. De autores, público, impresores y manuscritos en el Siglo de Oro", en Cuadernos de Historia Moderna, n. ${ }^{\circ}$ 18, Universidad Complutense (1997), pp. 31-50.

2 Al respecto, véanse: Bouza Álvarez, F.: Del escribano a la biblioteca. La civilización escrita europea en la Alta 
Edad Moderna (siglos XV-XVII), Madrid, Sintesis, 1992. De este mismo autor acaba de aparecer una sólida y fundamentada reflexión marcada por el rigor, acerca del papel otorgado al uso, disfrute y circulación de manuscritos, no en contraposición al libro impreso sino como referente coetáneo cultural de primer orden: Corre manuscrito. Una historia cultural del Siglo de Oro, Madrid, Marcial Pons, 2001. De los Reyes Gómez, Fermín: El libro en España y América. Legislación y censura (siglos XV-XVIII), Madrid, Arco/Libros, 2000. Este último estudio recoge de manera exhaustiva a lo largo de dos volúmenes los parámetros indicados, así como una bibliografía en la que se conjugan tanto las novedades como los estudios pioneros, ya clásicos, sobre el tema. A ella remitimos para un mayor conocimiento. W. AA.: Imprenta y crítica textual en el Siglo de Oro, Estudios publicados bajo la dirección de Francisco Rico, Valladolid, 2000.

3 Esta Pragmática, así como una síntesis de la política libraria desde los Reyes Católicos hasta Felipe II en García Oro, J: Los reyes..., op. cit., pp. 11-44. Más recientemente véase García Oro, J. y Portela Silva, M. J.: La monarquía y las letras en el Siglo de Oro, Alcalá de Henares, 1999.

4 González de Amezúa, op. cit., p. 334.

5 Pregmática sobre la impresión y libros... En Valladolid. En casa de Sebastián Martínez. 1558. Recogida en la Novísima Recopilación. Libro VIII. Título XVI. Ley III y Título XVIII, Ley I. Transcrita en De los Reyes Gómez, F.: op. cit., pp. 799-804. Cfr. García Oro, J: Los reyes..., op. cit., pp. 76 y ss. Doña Juana de Austria, serenísima princesa de Portugal, viuda del príncipe don Juan (1554) y madre del malogrado rey don Sebastián, actuaba como regente nombrada por su hermano Felipe II cuando éste se ausentaba del reino.

6 Autos y acuerdos del Consejo de que se halla memoria en los libros, desde el año de 1532 hasta el presente de 618. Mandados imprimir por el ilustrísimo señor don Fernando de Azeuedo, Arçobispo de Burgos, Presidente del Consejo y Señores del [Escudo real] En Madrid. Por Luis Sánchez Impresor del Rey N.S. Año de M. DC. XVIII [1618]. Biblioteca Nacional de Madrid, a partir de ahora BN. 2/58146.

7 Notata quaedam ex libris, quos ad ungen perlegi, eo, quo lecta sunt, ordine descripta... BN. Mss. 9226. Citado y trascrito por Gallardo, Bartolomé José: Ensayo de un Biblioteca española de libros raros y curiosos, Madrid, 1889, tomo IV, pp. 936-937. Existe ed. facsímil de Gredos, Madrid, 1968. Cfr. Bouza Álvarez, F.: Del escribano..., op. cit., p. 64 et alii.

8 Pérez Pastor, Cristóbal: Bibliografía madrileña, I, Madrid, 1891, n. ${ }^{\circ} 482$, pp. 248-250.

9 Suárez de Figueroa, Cristóbal: Plaza universal de todas ciencias y artes, parte traducida de toscano y parte compuesta por el doctor... A Don Duarte, Marqués de Frechilla y Villarramiel... En Madrid por Luis Sánchez, 1615. El título hace referencia a la obra del italiano Tomaso Garzón: La piazza universale di tutte le professsioni del mondo, traducida y ampliada por Suárez. Sólo a modo de curiosidad, siendo ésta una constante a lo largo del siglo, debemos constatar cómo las erratas van firmadas por el licenciado Murcia de la Llana.

10 lbid. Discurso CXI. De los impresores. Fols. 366-368v. ${ }^{\circ}$

11 Ibid. Discurso XXVII. Del arte de escribir de cifras, geroglíficos, ortografía y correctores. fols. $112 \mathrm{v}^{0}-119 \mathrm{v} .{ }^{\circ}$ La cita concretamente fol. $119 \mathrm{v}{ }^{\circ}$

12 Moreno Gallego, V.: op. cit., p. 1169.

13 La polémica creada y su resolución, se halla perfectamente ilustrada en García Oro, J.: Los reyes..., op. cit., pp. 82 y ss.

14 Existe un interesante memorial en A[rchivo] G[eneral] de S[imancas]. C.C. 523, recogido por García Oro, F.: Los reyes..., op. cit., pp. 85-86, en donde Vázquez del Mármol analiza las causas de las demoras producidas, así como la inconveniencia de nombrar un corrector para Sevilla. Su lentitud, según afirma, era debida a que corregía los libros enteramente de forma personal; la solución pasaba por nombrar colaboradores. Las presiones a las que se veían sometidos los correctores no se planteaban solamente por motivos de premura, sino que también iban encaminadas a influir en él para que no realizara grandes cambios en el texto, lo que parecía práctica común a juzgar por una carta de Francisco Sánchez de la Broza "El Brocense" a Vázquez del Mármol fechada el 19 de junio de 1588 en la cual manifiesta su malestar por no haber sido elegido corrector del claustro salmantino: "Yo dije alli que este oficio no se había de dar sino a hombres de confianza, y que lo que menos cumplía era darse a hombre que era familiar de los libreros, y mucho menos corrector de emprentas, porque pueden trocar, mudar, enmendar, trasponer, añadir, quitar de lo que viene refrendado de corte, y con un hombre de suerte y autoridad no se atreverán los libreros o autores de libros a mudar cosa de cómo viene de corte". Véase Bouza Álvarez, F.: Para qué imprimir..., op. cit., p. 37.

15 Nicolás, Antonio: Biblioteca Hispana Nova, Matriti, apud Joachimun de Ibarra Typographum regium, MDC- 
CLXXXIII, 2. ${ }^{a}$ ed., tomo I, p. 451 (1. ${ }^{a}$ ed. Roma, 1672). A continuación de la breve reseña, introduce un listado de sus obras.

16 Estos datos aparecen en el testamento de Francisco Murcia. Citado por Pérez Pastor, C.: op. cit., II, kk p. 388. El documento aludido se encuentra en A[rchivo] $\mathrm{H}$ [istórico] de P[rotocolos] de M[adrid]. Prot. n. ${ }^{\circ}$ 6119. esno Francisco de Medina. fols. 250-255v. ${ }^{\circ}$

17 Todos los datos que aparecen a continuación, salvo que se indique lo contrario, están tomados de Pérez Pastor, C.: op. cit., II.: pp. 385-388.

18 Sobre el particular resulta imprescindible el estudio de: Astrana Marín, Luis: Vida ejemplar y heróica de Miguel de Cervantes Saavedra, con mil documentos hasta ahora inéditos y numerosas ilustraciones y grabados de época, Instituto Editorial Reus, tomo V, Madrid, 1953, pp. 596-599.

19 AHPM. Prot. n. ${ }^{\circ}$ 6119. Esno. Francisco Medina. fol. $250 \mathrm{v}{ }^{\circ}$

20 Cédula real de 21 de Diciembre de 1612.

$21 \mathrm{El}$ memorial en $\mathrm{A}$ [rchivo] $\mathrm{H}$ [istórico] N[acional]. Secc. Consejos (Consulta de Gracia). Leg. 4421 n. ${ }^{\circ}$ 54. Fue dado a conocer y transcrito integramente por: Simón Díaz, J: "Algunas noticias cervantistas: El corrector del Quijote", en Revista Bibliográfica y Documental, 1948, Madrid, pp. 185-187.

22 La capellanía a la que hace referencia es la de los Reyes de Granada, ocupada por su antecesor en el cargo Vázquez del Mármol.

23 En cuanto a la rebaja propuesta en el pago de la corrección de pliegos, en el documento se deja ver claramente como Francisco Murcia había tenido que claudicar con anterioridad y bajar él mismo los precios para evitar la emigración de los originales a las aludidas ciudades.
24 Cédula real de 10 de diciembre de 1635.

25 AHN. Secc. Consejos (Consultas de Gracia) Leg. 1635 n. ${ }^{0}$ 135. Citado por Pérez Pastor, op. cit., III, p. 434.

26 Del matrimonio entre Francisco Murcia y Clara de Ribas, nacieron: Francisco, Carlos, Martín Javier, María, Jusepa, Catalina y Antonia.

27 La relación de estos acontecimientos se encuentra dispersos entre varios documentos que se realizaron a finales del XVII en base a una petición de la que posteriormente daremos cuenta. AHN. Secc. Consejos (Cámara de Castilla. Consultas de Gracia) Leg. 4441 n. ${ }^{\circ}$ 61. La escritura donde se otorgaba el título a doña María, se suscribió el 30 de octubre de 1636 bajo la escribanía de Carlos Pablo a la sazón cuñado de Francisco Murcia padre.

28 Dos de ellas debian haber profesado, según merced real concedida a su padre, en los conventos de Santa Isabel y San Bernardo de Alcalá de Henares, pero la gracia nunca se cumplió según se desprende de la lectura del testamento del cabeza de familia: AHPM. Prot. n. 6119. fol. $254 v^{\circ}$

29 AHPM. Prot. n. ${ }^{\circ}$ 3016. Esno. Juan Ruiz de Heredia. fol. 1278. Cfr. AHN. Secc. Consejos. Leg. 4441 n. ${ }^{\circ}$ 61. 23-julio1636.

30 AHPM. Prot. n. ${ }^{\circ}$ 6119. fols. 254$254 \mathrm{v}$. $^{\circ}$

31 Poco pudo disfrutar de esta asignación, pues doña María fallecía en la calle de las Huertas el 30 de diciembre, según se desprende del certificado del óbito que se encuentra en el Archivo parroquial de San Sebastián (Pérez Pastor, C.: op. cit. p. 388. Apenas un mes antes, también había fallecido su padre, encontrándose en el mismo archivo su partida de defunción, donde se dice que murió el 24 de noviembre de 1639 y mandó enterrarse en Santa María -este apartado se encuentra refrendado en su testamento-, la sepultura sería la misma donde ya se encontraba enterrada su mujer doña Clara de Ribas). En el Archivo de Santa María se localiza la partida del sepelio: "El licenciado Murcia de la Llana se trujo a enterrar á esta Iglesia de Santa María de la parroquia de San Sebastián. Enterrose en 24 de noviembre de 1639 en sepultura propia junto al altar de Lorenzana; dieron de rompimiento ocho reales". Pérez Pastor, C.: op. cit., II y mm p. 388.

32 AHN. Secc. Consejos. Leg. 4441 n. ${ }^{\circ}$ 61. 26-febrero-1665.

33 AHN. Secc. Consejos. Leg. 4441 n. 61. 17-abril-1651 (Traslado de escritura en 12-junio-1652).

34 Canciones lúgubres y tristes, a la muerte de don Cristóbal de Oñate. Teniente de Gobernador, y Capitan General de las conquistas del nuevo México. Compuestas por Francisco Murcia de la Llana, profesor de letras humanas. Dirigidas a don Juan de Oñate, Adelantado y Conquistador del nuevo México. Con Licencia. En Madrid, Por la Viuda de Fernando Cortez. Año de M.DC.XXII. Que sepamos sólo existe un ejemplar de este libro en la John Carter Brown Library de Providence (Rhode Island); sobre ésta se realizó una edición facsimilar con estudio preliminar de Agapito Rey y José Manuel Blecua. Col. Duque y Marqués. Opúsculos literarios rarísimos. La fonte que mana y corre... Valencia, 1953. Según se desprende de las palabras del propio Francisco, parece ser que esta edición debió mucho a su padre: "Y aunque es verdad, que a mi padre (espejo en quien yo examino mis acciones) le 
incumbía este negocio mucho más noblemente que a $\mathrm{mi}_{\text {, }}$ porque en el venero grandes, y venerables letras..." p. 49. A tanto pudo llegar, que incluso Antonio Nicolás en la relación de obras del susodicho la incluye como obra de su progenitor.

35 Vega y Carpio, Félix Lope de: Laurel de Apolo, Ed. Juan González, Madrid, 1630. Silva octava. fols. $72 v^{\circ}{ }^{-73}$. Lope conocía perfectamente el librito de De la Llana, pues fue el encargado de realizar la aprobación del mismo; tras su estudio no encontró reparo y la firmó en Madrid en 28 de abril de 1622.

36 Cédula real de 26 de febrero de 1665. Copia en AHN. Secc. Consejos. Leg. 4441 n. ${ }^{\circ}$ 61. La petición de la plaza se realizó el 28 de enero.

37 Ibid. 23-mayo-1668.

38 lbid. 7-junio-1668.

39 Ibid. 7-enero-1669. Había testado ante Pedro Navajas en 26 de diciembre de 1668.

$40 \mathrm{El}$ pleito se encuentra recogido en AHN. Secc. Universidades. Libro 1134. fols. $19 v{ }^{\circ}-23 v .{ }^{0}$

41 Diego de Bárcena, había sido nombrado el 16 de abril de 1664. AHN. Secc. Universidades. Libro 1133. fol. 223. Con anterioridad y por estar vacante el puesto el 29 de junio de 1632 se había elegido al maestro Alonso Sánchez de Moratalla. AHN. Secc. Universidades. Libro 1132 fol. 18.

42 AHN. Secc. Universidades. Libro 1134. fols. $22 v .^{\circ}-23 v{ }^{\circ}$

43 AHN. Secc. Consejos Leg. 4441 n. 61. $\mathrm{s} / \mathrm{f}$ c. 1709.

44 AHN. Secc. Órdenes Militares. Santiago. Expedientillo n. ${ }^{\circ}$ 4399. Para la obtención del hábito, Martín Javier, tuvo que pasar de forma obligatoria, aunque no lo conservemos, por un estudio de su pasado tendente a verificar su limpieza de sangre. Resulta curioso comprobar cómo su padre muchos años antes habia criticado ciertas prácticas sobre esta fórmula; sus apreciaciones fueron impresas en: Discurso político del desempeño del Reyno, seguro de la mar, y defensa de las costas de la Monarquía de España. A la Majestad Católica. En Madrid XXI de Mayo. Año M. DC.XXXIIII, de don Francisco Murcia de la Llana (sin foliar). BN. R/31550. Fue citado y transcrito por: Caro Baroja, Julio: Los judíos en la España Moderna y Contemporánea, Ed. Istmo, Col. Fundamentos, vol. II, Madrid, 1978, pp. 346-348.
45 Estas últimas noticias fueron dadas a conocer por Álvarez Baena: op. cit., p. 203, en la enmarañada biografía de su hermano Francisco.

46 CARTILLA,/ EN QUE SE PROPONEN/ las Reglas, para Torear a Ca/ ballo, y practicar este Valeroso, Noble Exercicio, con/ toda destreza./ DISPUESTA/ POR DON NICOLAS RODRIGO/ Noveli./ QUIEN DEDICA/ AL EXC.mo SEÑOR DUQUE/ del arco, caballerizo Mayor de el/ Rey nuestro señor, \& c./ Con licencia: En Madrid En la Imprenta/de Angel Pasqual Rubio. Año/ de 1726. Existe un facsímil con título: Reglas para torear a caballo por don Nicolás Rodrigo Noveli (Reimpresión integra de la edición de 1726) Madrid MDCCCXCIV [1894]. BN. R/ 13803.

47 NUEVA FEE DE ERRATAS POR CORRECTOR ANTIGVO, a la recien impressa Cartilla, en que se proponen las reglas para torear a caballo, por Don Nicolás Rodrigo Nobeli, este presente año de 1726. Foliación a mano 424-427v. ${ }^{\circ}$ Este impreso se encuentra conjuntamente encuadernado con otras muchas cartas recopiladas por Pascual Gayangos, en BN. 3/33206.

48 Nueva fee de erratas..., op. cit., fol. $427 v^{\circ}$ 